\title{
Intellectual Provision of the Innovative Entrepreneurship Development
}

Tatiana Lebedeva1

Evgeny Egorov 1

Tatiana Tsapina ${ }^{2}$

Tatiana Fokina ${ }^{3}$

Tatiana Vasilyeva ${ }^{3}$

${ }^{1}$ Minin Nizhny Novgorod State Pedagogical University

${ }^{2}$ Nizhny Novgorod University of Architecture and Civil Engineering ${ }_{3}^{3}$ Moscow Humanitarian - Economic Institute; Email: tatyana.lebedeva@bk.ru

Doi:10.5901/mjss.2015.v6n5s3p303

\section{Abstract}

A particular relevance of intellectualization of entrepreneurship is proved in the article. It is offered the concept of "intellectual securing for entrepreneurship". The intellectual securing provides the organization and self-organization of continuous information and knowledge torrents in the system "education-science-entrepreneurship". Intellectual entrepreneurship is considered as the result of the integration of science and entrepreneurship and the channel of transfer's knowledge between them. The authors have proved that the education system should be a key integrator of intelligent and innovative securing of economic subjects. The results of more than a decade experience of formation the professionally significant personal qualities for an entrepreneur are discussed by authors. It is compared and justified the pedagogical approaches, methods and didactic means (with an actualization of attention to the training technology -a fragment of the training is presented, directed to a creative solution of a real situation) of personal qualities' formation, allowing to enter to the business intellectual field. The main results of conducted investigation were: the creation of a complex intellectual supporting of innovative entrepreneurship's development within the educational courses at the university; development of didactic means allowing to identify necessary qualities of the entrepreneur in a business intelligence environment; creating and testing an optimal model of course allowing to prepare an intellectual entrepreneur.

Keywords: Innovation in the entrepreneurship, providing innovative complex intelligent enterprise development, didactic means.

\section{Introduction}

The result of the information revolution is increasing the number of people engaged in intellectual work. At this stage of development of social production in, its structure along with direct human abilities to work organically includes the ability to intellectual activity. There are being increased the requirements to the intellectual and creative capacities of a human being. However, along with the "information economy" the new term is widely spread, which reflects the new content of the economic development, having become a paradigm of progress - the knowledge economy (Knowledge Economy: Lessons for Russia, 2012).

At present the doubtless fact is that the intellectualization takes place in many acivity areas:

- Intellectualization of work;

- Intellectualization of education;

- Intellectualization of information activity;

- Intellectualization economy - the transition to a knowledge economy, the formation of brain capital.

The process of the work intellectualization is a process of using and forming the intellectually significant possibilities and abilities. It is due to the advent of a large number of tasks in the working activity that require nonstandard \& innovative approaches and solutions in the various aspects of professional activity. This highlights the intellectual costs (for the production of knowledge, information) that results in a modification of the work functional structure (Huizingh, 2011).

The essence of the intellectual work reflects a system of economic relations, the content of which is the production 
of new knowledge. It is expressed in the fact that in the process of intellectual work the following occurs: 1) The consumption of skilled labor and the use of abilities of employees; 2) objectification of the productive forces in certain results that have both the material (real) and not material (ideas, discoveries, etc.) forms of embodiment; 3 ) selfdevelopment of a human being creative powers, the implementation of its essential nature (Egorov, 2004).

The overview of the knowledge economy requirements to the society and the analysis of the current level of development of Russia and its intellectual sphere allows identifying the following problems:

- The lack of interaction between the science and education system and entrepreneurship system to implement counter technological transfer;

- Inefficient use of intellectual resources of the country: the nonconformity of the country economic structure to the qualification structure of labor resources, poor development of the intellectual entrepreneurship

- Undeveloped infrastructure of the knowledge economy, especially its information \& communication sector;

- Undeveloped institutional environment of the knowledge economy - the lack of the effective protection system of intellectual property rights, economic incentives for the development of intellectual products (innovations), state support for the innovative entrepreneurship and entrepreneurial culture (Robinson and Blenker, 2014).

The overcoming of the problems identified, in our opinion, is only possible in the implementation of integrated state policy aimed at the development of conditions conducive to reproduction and effective use of intellectual resources.

It may be also emphasized that the overall gap of Russia in the field of development of the knowledge economy acquires the importance of searching effective models, mechanisms and tools for the intellectual support of the innovative development of the country and its market subjects, including entrepreneurship.

As we know, the knowledge economy is fundamentally changing all the traditional development principles, approaches and models of competitive entrepreneurship. The entrepreneurship in the knowledge economy is more and more focused on efficiency and maximizing the market value of the companies in which intangible assets are of greater importance in main share (technology, marketing, client, consumer, etc.), which are a consequence of the effective use of the company intellectual capital.

Consequently, the role of effective strategic management of intellectual resources is increased in the conditions of the knowledge economy since along with the use of the intellectual capital of the company there is formed a competitive market environment.

\section{Analysis of the Main Publications}

The analysis of the modern literature on entrepreneurship shows that many scientists are beginning to focus increasingly on the intellectual entrepreneurship phenomenon, typical for the knowledge economy.

The notion of intellectual entrepreneurship is a relatively new and little explored. In the most basic approximation, the intellectual entrepreneurship is an entrepreneurship carried out by the intellectuals, i.e. by the people with higher education, the activity result of which is the intellectual product. The important characteristics of the intellectual entrepreneurship are development of socially-oriented complex products, a focus on self-realization (as opposed to the deriving of the economic benefit only), the high proportion of labor costs in total production costs.

Intellectual entrepreneurship includes:

- Entrepreneurship in science;

- Entrepreneurship in the creative work;

- Entrepreneurship in consulting;

- Entrepreneurship in education and management;

- Entrepreneurship in the field of providing the information monitoring, etc.

The development of intellectual entrepreneurship can go in two directions. First, the intellectuals, on their own initiative, are engaged to the economic activity. The basis of this trend is a fundamental change in the traditional role of intellectuals influenced by social and political reforms as well as the growth of the attractiveness of the entrepreneurial career and its prospects which are aligned with other economic and social activities.

Second, the entrepreneurship area itself becomes the object of "intellectualization." The basis here is to improve the professional training and increase general educational level followed by the expansion of the horizon up to the global views.

The ongoing systemic transformation of the economy and society and the transition to a knowledge economy increase the value of the educational system in the society and economy. The universities' need to adapt to the changing requirements of the external socio-economic environment is realized at the level of the whole country, and at the level of individual educational institutions. Modern universities are expanding goals and enriched with functions. The universities 
are not limited by solving the tasks to provide highly qualified specialists for the economy; they will intensify activities in the field of research and development, develop innovative activity, and become regional centers of the entrepreneurial activity (Lebedeva, Egorov, Vakulenko, Stouhina, 2014).

One of the ways to integrate the education and science system with the entrepreneurship are the small firms organized at universities in which teachers and students are showing themselves as entrepreneurs creating and promoting their innovations to market.

The strategy of innovative development of the Russian Federation until 2020 "Innovative Russia - 2020" identifies a number of major problems that are associated with the development of the education sector:

- Change people, increase their receptivity to innovation, extend the class of innovative entrepreneurs, create an atmosphere of tolerance for risk in society;

- Increase the innovative business activity and dynamics of founding new innovative companies (Egorov, Lebedeva, Bulganina and Vasilyeva, 2015).

The "change" of young people is the historic mission of higher educational institutions. The growth of the number of innovative companies is hardly possible without an accent of universities to promote entrepreneurship and motivation in learning. The improving training performance (e.g., growth in the number of university graduates in high-tech companies) is usually achieved due to balance of the sectors of research and teaching at a university. All of the above shows the close connection between the development of the higher education system and the formation of an innovative component of the Russian economy.

According to S.M. Klimov, the intellectual products and services occupy increasingly important place on the international markets. According to expert estimates, the global market for intellectual goods and services is growing five times faster than traditional markets.

In other words, the competition becomes multilevel, penetrating as well the internal environment of the firm, and the firm should be competitive at every level of both external and internal environment. In the external environment, the role of interaction with its partners in the networks is increasing which are becoming the major economic subjects of the new economy (as opposed to corporations in the industrial economy). In the internal environment, the firm employees exert the more important influence on its competitiveness; their competitiveness directly determines the competitiveness of the organization.

The intellectualization of work is associated with the dominance of the economic function of education. Here the connection of universities and institutes of higher education to the economy can be seen through the market of professional manpower, research and applied sciences and through the expanding consumption of "high culture." In other words, the traditional functions of higher education - knowledge for knowledge's sake, reproduction of the ruling and cultural elite - have been supplemented by economic function. This process is reflected in the establishment of universities which are special forms of entrepreneurship.

They function as research centers for the purpose of technological innovation on the principle of "research on assignment" and completely dependent on the customer finance and interests.

For the development of intellectual resources in the system of the entrepreneurial work it is necessary to develop clear priorities of long-term state economical policy. At this, the system of education should become the integrator of intellectual support of economic subjects.

The innovative development of the entrepreneurship involves the introduction of the innovation of all types by any business structures in their activities - technical, organizational, marketing and other in order to develop their own competitiveness. The evolutionary transition of the entrepreneurship to innovative development requires a change of the methodological approach to the study and management of this process: from the linear equilibrium approach that views an entrepreneur as a dependent on an environment to synergistic one that provides an interactive interaction of the entrepreneur and environment (Ferrary, 2011).

The transition to an innovative model of economic growth is impossible without building a new mechanism of social development based on the balance of creative freedom of the individual, entrepreneurial freedom, social justice and national competitiveness. And it is the intellectual potential of labor resources determines the level of national education, science, innovation and technological development, labor productivity growth in all countries.

Under the intellectual support of innovative development of entrepreneurship there is the continuous process of reproduction of the intellectual resources of the country, as well as generating, sharing and distribution of knowledge structured in theoretical and methodological, institutional and structural and technological and practical aspects, between the subjects of the discussed system being at its different levels (macro, meso, micro and nano) providing the basis for development knowledgeable competitiveness of business structures. 


\subsection{Intellectualization of innovative entrepreneurial activity}

The intellectualization process is the process of use and formation of intellectually significant possibilities and abilities. It is caused by the appearance of a large number of tasks in the working activity that requires the non-standard innovative approaches and solutions in various aspects of professional activity. This highlights the intellectual expenses (for the production of knowledge, information), which results in a modification of the functional structure of the labor (Egorov, 2004).

As we know, the knowledge economy fundamentally changes all the traditional principles, approaches and models of development.

The analysis of the modern literature on entrepreneurship shows that many scientists are beginning to pay more attention to the phenomenon of intellectual entrepreneurship typical for the knowledge economy. The concept of the intellectual entrepreneurship is quite new and poorly studied. In the most basic approximation, the intellectual entrepreneurship is a entrepreneurship carrying out by intellectuals, that is, by the people with higher education, the results of whose activity is the intellectual product (Dahlander and Gann, 2010).

The intellectualization of the entrepreneurship creates the conditions for increasing the role of education as a basis for the formation and development of intellectual resources, the creation and transfer of new knowledge in the economy (Baklashova, 2014). The education system inevitably becomes closer to the entrepreneurship, integrates with it, which contributes to more effective sharing of knowledge, the introduction of more advanced scientific methods of production, the education and spiritual growth of entrepreneurship, forcing it to serve the interests of society, not just personal gain.

For effective implementation of this task the relationship between the education and entrepreneurship systems must change, which are separated and developed independently, what hampers the processes of intellectualization and entrepreneurship.

The strategy of innovative development of the Russian Federation for the period up to 2020 "Innovative Russia 2020" identifies a number of basic tasks that are associated with the development of the education sector: - to change people, increase their susceptibility to innovations, expand the class of innovative entrepreneurs, to create an atmosphere of tolerance to risk in the society; - to increase the innovative activity of the business and the dynamics of the emergence of new innovative companies (Bianchi, Cavaliere, Chiaroni, Frattini and Chiesa, 2011).

\subsection{Pedagogical approaches and the development results of the personality traits in the process of intellectualization of the entrepreneurial activity}

Refer to educational technologies, contributing to the development of entrepreneurial knowledge and personal traits, allowing to be successful in the process of the entrepreneurship intellectualization (Hsu, Tan, Laosirihongthong, 2014).

The developed technology of training and development of professionally important qualities is worked out and perfected over a decade in the Minin State Pedagogical University. The result of its use is a proved development of professionally important traits of an entrepreneur.

The formation technology of professionally important traits is set up on the basis of the known provisions developed by B.I.Teplov, V.D.Shadrikov. The main idea is that the professionally important traits are understood as a product of lifelong formation. The determining role in this process is training which leads the development.

The idea of the development of traits is carried out in the preparation process of participants under a refresher course "Technologies of modern entrepreneurship" (which consists of modular programs selected by participants).

The study was conducted on the basis of the Nizhny Novgorod State Kozma Minin Pedagogical University for 10 years (2004-2014). In the experiment, there were participated 498 people under a refresher course on the program "Technologies of modern entrepreneurship". The purpose of an experimental study was the validation of the developed theoretical positions as well as working out the optimal model of course allowing preparing an entrepreneur ready for the challenges of the time.

The objective of the course was the preparation of the entrepreneur-practitioner. Consequently, during the experimental study it was necessary to evaluate:

1. The digestion level of the background knowledge on the basics of entrepreneurial activity, management and marketing.

2. The level of formation of professional motivation for entrepreneurial activity.

3. The degree of readiness for practical entrepreneurial activity.

4. The development of entrepreneurial skills.

Let's see each direction in more detail. 
1. The digestion of the background knowledge for each discipline was estimated:

a) in the course of the knowledge digestion (during lectures);

b) after working out the knowledge (current control via intermediate levels - level tasks);

c) during resulting test (at the reportable events).

Table 1 shows the fulfillment results of the level tasks by the course participants at the lectures in the first stage of the experimental study.

Table 1 - The fulfillment results of the level tasks in the digestion process of the background knowledge of the module "Basics of entrepreneurial activity"

\begin{tabular}{|c|c|c|c|c|}
\hline $\begin{array}{l}\text { Ser. } \\
\text { No }\end{array}$ & Module subject & \multicolumn{3}{|c|}{$\begin{array}{l}\text { The number of students coped with the } \\
\text { task (\%) }\end{array}$} \\
\hline & Task level & I & II & III \\
\hline 1. & Entrepreneurship: the nature, goals, objectives & 60 & - & - \\
\hline 2. & Principles and forms of entrepreneurship & - & 69 & - \\
\hline 3. & Technology of creating an enterprise & - & - & 59 \\
\hline 4. & Internal and external environment of the firm functioning. & - & 72 & - \\
\hline 5. & Management in the activity of entrepreneur and teacher & - & 82 & - \\
\hline 6. & Labor collective. Productivity and remuneration of labor. & 54 & - & - \\
\hline 7. & Marketing in the activity of entrepreneur. & - & - & 78 \\
\hline 8. & Product development process & & & 68 \\
\hline 9. & Small business development & & 64 & \\
\hline 10. & $\begin{array}{l}\text { Financial activities of the entrepreneur. The concept of accounting. Investing in } \\
\text { entrepreneurial activity }\end{array}$ & 53 & - & - \\
\hline 11. & $\begin{array}{l}\text { Entrepreneurial activity and taxation of entrepreneurial firms. State regulation of } \\
\text { entrepreneurial activity }\end{array}$ & 71 & - & - \\
\hline 12. & Analysis of the performance of enterprises under market economy conditions & 45 & - & - \\
\hline 13. & Fundamentals of Business Law & - & - & 48 \\
\hline 14. & Business ethics and morality & - & - & 60 \\
\hline 15. & Entrepreneurial activity at educational institutions & - & 73 & - \\
\hline The al & erage number of students coped with the tasks of each level & 56,5 & 73,4 & 62,5 \\
\hline
\end{tabular}

Source: study of authors of this article

As we can see from Table 1, on the first phase lectures the course participants were offered the tasks of all levels. The surprising fact was (it can clearly be seen in Table 2) that the course participants coped with the second and third level tasks better than with the tasks of the first level.

2. The level of formation of professional motivation for entrepreneurial activity. At the first stage of the experimental study the task of formation of professional motivation to the practical entrepreneurial activity was not set since the courses were attended by people with the need to acquire professional knowledge enhancing their competence in the business (Duval-Couetil and Gotch Yi S., 2014).

Meanwhile, to determine the effect on the course participants the survey was conducted. The results of the survey showed an increase in the level of motivation for the entrepreneurial activity (from $54 \%$ - up to $61 \%$ - in different groups of the course participants).

3. The degree of readiness for practical entrepreneurial activity. The fact that the course developed by us really allows to prepare a participant to the practical entrepreneurial activity is confirmed by talks conducted with entrepreneurs (27 people) - representatives of real business.

During the talks conducted with every entrepreneur there were offered the following questions:

1. Is the successful implementation of the practical entrepreneurial activity possible without additional specialized training?

2. They say that one must be born as an entrepreneur. Then, is it necessary in the preparation of the entrepreneur-practitioner to use special forms of work (business games, trainings and other) aimed at developing entrepreneurial skills?

3. Knowledge of what main issues addressed in the course proved to be most useful for the practical organization of entrepreneurial activity?

The results of the talks with entrepreneurs-practitioners have concluded that the methods and forms of education 
used in the process of teaching not only promote the development of entrepreneurial skills, but also motivate future specialists to the professional activity and develop reflective abilities.

4. The development of entrepreneurial skills. To identify the baseline of the studied qualities - creative potential, sociability, initiative, working ability, ability to take risks there were used valid test methods. For all applied tests the nine level rating scale was used to interpret the development indicators of skills: level 1 - very low level of development of appropriate skill; level 2 - low; level 3 - below medium; level 4 - slightly below medium; level 5 - medium; level 6 - slightly above medium; level 7 - above medium; level 8 - high; level 9 - very high level of development.

It is known that an entrepreneur should possess all the skills we have dedicated at the level of their development not below medium. This assertion is proved by the results of our testing of practicing entrepreneurs (27 people). They are given in table 2.

Table 2: Development of entrepreneurial skills among entrepreneurs-practitioners

\begin{tabular}{|c|c|c|c|c|c|c|c|c|c|c|}
\hline \multirow[b]{2}{*}{ Ser. No. } & Entrepreneurial skills & \multicolumn{9}{|c|}{ Indicator of development(in \% of the total number tested) } \\
\hline & & 1 & 2 & 3 & 4 & 5 & 6 & 7 & 8 & 9 \\
\hline 1. & Creative potential & - & - & - & - & - & 2,7 & 19 & 27 & 51,3 \\
\hline 2. & Sociability & - & - & - & - & - & - & - & 21,6 & 78,4 \\
\hline 3. & Initiative & - & - & - & - & 5,3 & 13,5 & 43,2 & 19 & 19 \\
\hline 4. & Working ability & - & - & - & - & - & - & 3 & 10 & 24 \\
\hline 5. & Ability to take risks & - & - & - & - & - & 6 & 16 & 10 & 5 \\
\hline
\end{tabular}

Source: study of authors of this article

As we can see from Table 2, the vast majority of entrepreneurs-practitioners have entrepreneurial skills listed above at the levels above the medium. Especially, there are developed such skills among them as sociability and working ability.

With the help of these tests, at the beginning of the first phase of the experiment before the study of the course there was made the cut for identifying the baseline of the studied entrepreneurial skills. The test results are given in Table 3.

Table 3 - The monitoring results of entrepreneurial skills among the course participants learning the course "Technologies of modern entrepreneurship"

\begin{tabular}{|c|c|c|c|c|c|c|c|c|c|}
\hline \multirow{2}{*}{ Ser. No. } & Entrepreneurial skills & \multicolumn{8}{|c|}{ Indicator of development (in \% of the total number tested) } \\
\hline & tevel of development & 1 & 2 & 3 & 4 & 5 & 6 & 7 & 8 \\
\hline 1 & Creative potential & - & - & - & 38,9 & 44,4 & 16,7 & - & - \\
\hline 2 & Sociability & - & 7 & 18 & 22, & 30,6 & 16,6 & 5,6 & - \\
\hline 3 & Initiative & 8,3 & 19,4 & 27,8 & 31 & 5,6 & 4, & 2,8 & \\
\hline 4 & Working ability & 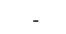 & 15,3 & 26,4 & 34,6 & 7 & 8,3 & 5,6 & 2,8 \\
\hline 5 & Ability to take risks & 16,6 & 37,5 & 37,5 & 1,4 & 7 & - & - & - \\
\hline
\end{tabular}

Source: study of authors of this article

Table 3 shows that before learning the course the skills among the most of the course participants were developed below the medium level. The highest indicators can be seen on sociability and creative potential. Upon further investigation, we paid special attention to the least developed skills: initiative, working ability, ability to take risks.

At the end of the study of the course there was conducted a control cut using the same tests as in the beginning of the experiment. The test results showed the increase of the development level of four of the five studied traits. Table 4 presents the monitoring results of the development of the entrepreneurial skills. 
Table 4 - The development of entrepreneurial skills among the course participants before and after learning the course "Technologies of modern entrepreneurship"

\begin{tabular}{|c|c|c|c|c|c|c|}
\hline e personality traits to be developed & 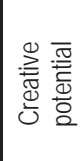 & 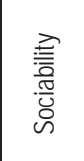 & 墨营 & 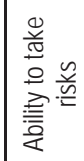 & 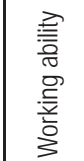 & 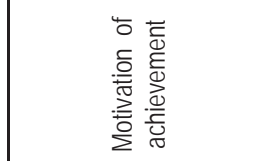 \\
\hline $\begin{array}{l}\text { Jumber of students (\%) showed levels of quality above medium } \\
\text { Difference in \% }\end{array}$ & $\begin{array}{c}\overline{25} \mid \overline{47} \\
22\end{array}$ & $\begin{array}{c}\overline{45} \mid \overline{86} \\
41\end{array}$ & $\begin{array}{c}35 \mid \overline{53} \\
18\end{array}$ & $\begin{array}{c}\overline{49} \mid \overline{55} \\
6\end{array}$ & $\begin{array}{c}\overline{24} \mid \overline{47} \\
23\end{array}$ & \begin{tabular}{|l} 
Increased on average by \\
27
\end{tabular} \\
\hline
\end{tabular}

Source: study of authors of this article

After statistical processing of the data presented in Table 4, it can be asserted that the course really helps to prepare the entrepreneur-practitioner.

Next we turn to the training technologies, since they are the most efficient (Zalyaeva and Solodkova, 2014). Using the training technologies in the educational process is quite effective as the initial and the final stages of training, when the professional competence of the participant-entrepreneur is intensively formed.

So in the module "Advertising technologies" each trainee is given an individual economic task that is as close to a real situation (developing promotional product). We give the example of the practical lesson on the subject "Development of a slogan". The lesson is designed for 1 hour 30 minutes. The course of the lesson can be represented as follows:

Mini-lecture "Development of a slogan" (20 minutes).

1. Exercise: "Options for the development of the slogan" (60 minutes)

The course participants are distributed into micro groups. Each group is asked to select the object to develop a slogan (by lot), then the course participants work out the proposed algorithm. At the beginning each student develops his own versions of the advertising slogans, then the exchange of the slogans takes place in the micro groups and the choice of "super slogan". Further, the results are given in the form of presentations.

2. Back feed (10 minutes)

Questions:

Which of the slogans may be effective for the "life" of the product?

Which of the presentations of the slogan is memorable?

The practice shows that the training technologies are quite effective during training of the specialists in various fields of business, because they allow not only forming the professionally important competencies, but also to develop the ability to assess the degree of ownership of these competencies and to reflect own activity (Lebedeva, 2012).

So, the motivation of the achievement after studying the course "Entrepreneurship" increases on average by $30 \%$, creative approach - by $20 \%$, initiative - by $20 \%$, working ability - by $25 \%$, sociability - by $40 \%$.

All this contributes to increase of the share of intellectual products and services in the total amount in the production of goods. According to S.M. Klimov, the intellectual products and services take increasingly important place in the international markets.

\section{Conclusion}

In conducting this study, the authors became apparent that the development of innovative entrepreneurship is impossible without the use of the modern approaches to the training of entrepreneurs. Meanwhile, the training of entrepreneurpractitioner should be systematic, both from the point of practical knowledge and from a position of the readiness and development of the critical professionally significant skills of the personality. On this basis, we can formulate a number of the practical recommendations for optimizing the use of scientific and educational potential for the development of the entrepreneurship.

Firstly, the innovative development of the entrepreneurship is impossible without intellectual support. Based on this requirement, it can be asserted that all the processes of the development of the entrepreneurship should be designed on the basis of "education- entrepreneurship".

Secondly, in the era of knowledge economy, all the internal and external environment of the entrepreneurship should be formed through the knowledge management. 
Third, it is clear that the entrepreneurs-practitioners are unlikely to "sit at the desk," and now the process of their preparation is realized primarily through the refresher courses. Therefore, the special attention should be paid to a complex of didactic tools contributing to the polyinformative preparation of an entrepreneur.

Thus, the intellectual support of the innovative development of entrepreneurship provides for the organization and self-organization of continuous counter-information-knowledge flows in the system of "education - science entrepreneurship" that contributes to the development of competences and "knowledge" competitiveness of all participants of the process of the innovative development at all levels of the interaction.

As the main participants of the innovative support of the intellectual development of entrepreneurship it is possible to highlight the following subjects of the education and science system (universities, scientific institutions), the system of entrepreneurship (large, medium and small businesses), the state and its institutions. The intellectual entrepreneurship is considered as a result of the integration of the science and entrepreneurship and the knowledge transfer channel between them. Each of them has an active influence on the state and development of all elements of the innovative support of the intellectual development of entrepreneurship, and the effectiveness of their interaction determines the efficiency of the reproduction of intellectual resources, as well as the exchange and dissemination of the knowledge in society (the country), which ensures the development of the "knowledge" competitive ability of the economic parties at all levels of socio-economic system. For the development of the intellectual resources in the country it is necessary, first of all, to develop the development strategy for the education system appropriate to the state policy. The education system should be a key integrator of the intellectual and innovative support of the economic parties.

\section{References}

Baklashova, T. (2014) Managers' Professional Training in Russia: Syllabus and Technologies. Procedia - Social and Behavioral Sciences. Vol. 152. pp. 1057-1061.

Bianchi, M., Cavaliere A., Chiaroni D., Frattini F. \& Chiesa V. (2011) Organisational Modes for Open Innovation in the Biopharmaceutical Industry: An Exploratory Analysis. Technovation. Vol. 31. pp. 22-33.

Dahlander, L. \& Gann D.M. (2010) How open is innovation? Research Policy. Vol. 39. pp. 699-709.

Duval-Couetil, N. \& Gotch Yi.S. (2014) The Characteristics and Motivations of Contemporary Entrepreneurship Students Journal of Education for Business Volume 89, Issue 8, DOI: 10.1080 / 08832323.2014.933156 pp. 441-449.

Egorov, E., Lebedeva T., Bulganina S. \& Vasilyeva L.(2015) Some Aspects of the Implementation of the Principle of Transparency in Russian Universities: Research, Experience, Perspectives International Education Studies; Vol. 8, No. 5; 2015 Published by Canadian Center of Science and Education 191-204

Egorov, E.E. (2004) Motivacija i stimulirovanie truda v upravlenii personalom Volzh. gos. inzhener.-ped. akad.. N. Novgorod.: N/Novgorod: VGIPU.

Ferrary, M. (2011) Specialized organizations and ambidextrous clusters in the open innovation paradigm. European Management Journal. Vol. 29. pp. 181-192.

Hsu, C-C, Tan K. \& Laosirihongthong T. (2014) Corporate entrepreneurship, operations core competency and innovation in emerging economies. International Journal of Production Research Volume 52, Issue 18, DOI: 10.1080/00207543.2014.915069 pp. 54675483

Huizingh, E. (2011) Open innovation: State of the art and future perspectives. Technovation. Vol. 31. pp. 2-9.

Knowledge Economy: Lessons for Russia (research report) (2012). - Moscow: CEMI RAN.

Lebedeva, T.E. (2012) Treningovye tehnologii pri podgotovke specialista v vuze. VIII Mezhdunarodnoj nauch.-prakt. konf. Dni nauki 2012, Publishing House "Education and Science" s.r.o. (Chehija, Praga), pp. 55-60.

Lebedeva, T.E., Egorov E.E., Vakulenko R.Y. \& Stouhina N.Y. (2014) Innovation aspects of managing bachelor training program in the context of Bologna Process in Russia. Life Sci J vol.11(10), pp. 533-537.

Robinson, S. \& Blenker P. (2014) Tensions between rhetoric and practice in entrepreneurship education; an ethnography from Danish higher education European Journal of Higher Education Volume 4, Issue 1, Special Issue: Ethnographies of Higher Education DOI:10.1080 / 21568235.2013 .853621 pp. 80-93

Zalyaeva, E. \& Solodkova I. (2014) Teacher-student Collaboration: Institute of Economics and Finance Kazan Federal University Approach // Procedia - Social and Behavioral Sciences, ERPA International Congress on Education, ERPA Congress 2014, 6-8 June 2014, Istanbul, Turkey Vol.152. 7 Oct. 2014, pp. 1039-1044. 